\title{
HUBUNGAN MUTU PELAYANAN KESEHATAN DENGAN KEPUASAN PASIEN BPJS RAWAT INAP DI RUMAH SAKIT SANTA ELISABETH MEDAN TAHUN 2019
}

\author{
Andri Simalango(1) \\ Universitas Prima Indonesia \\ Jalan Sekip Jalan Sikambing No.Simpang, Sei Putih Tim. I, Kec. Medan Petisah, Kota \\ Medan, Sumatera Utara 20111 \\ Email: Andri.unpri@gmail.com \\ Doi: https://doi.org/10.35451/jkg.v2i1.227
}

\begin{abstract}
Health is a human need that is desired by everyone. Maintaining the quality of a health service is very influential on the skills and abilities of the institution to maintain the good name of the company to attract customers to seek treatment. Service can be felt good by the patient if the way the treatment is more than what the patient wants. The quality of services can be seen from the ability of skilled hospitals in each field. The purpose of the study was to find out physical evidence, reliability, responsiveness, assurance, and attention to patient satisfaction. Satistic test on data analysis using the chi-square test $95 \%$ confidence level using the SPSS program. The study population was BPJS patients with a sample of 85 people. This research was conducted in May-June 2019 and data were collected by interview and using a questionnaire tool. The results showed that the $p$-value between Physical Evidence ( $p$-value 0.013), Reliability ( $p$-value 0.002), Responsiveness ( $p$-value 0.023), Guarantee ( $p$ value 1,000 ) and empathy ( $p$-value 0.110 ) on BPJS Patient Satisfaction. The conclusion of this study is that there is a relationship between physical evidence, reliability, responsiveness and there is no relationship between guarantee and attention to patient satisfaction. Suggestions for health workers are expected to improve performance again such as, nurses hold regular observations to check the development of the patient's health condition.
\end{abstract}

Keywords: Service Quality, BPJS Patient Satisfaction, Inpatient.

\section{PENDAhUlUan}

Dari segi Sumber Daya Manusia (SDM), kualitas pelayanan di Indonesia dalam aspek, jumlah, kualitas dan penyebarannya terus membaik. Pada tahun 2014 capaian persentase fasilitas pelayanan memiliki sebesar $85,50 \%$ melampaui target yang ditetapkan $80 \%$ dengan demikian capaian kinerjanya $106,88 \%$ (Kemenkes, 2015).

Pada tahun 2014, pemerintah Indonesia mendirikan Sistem Jaminan Kesehatan (BPJS). Semua orang yang tinggal di Indonesia harus memiliki kartu BPJS dengan membayar iuran perbulan sesuai premi (Peraturan BPJS NO 1, 2014).

Hasil Balitbang Kota Medan pada tahun (2013) Tingkat Kepuasan Jamkesmas di RSUD Dr. Pirngadi pada dimensi kehandalan 63,3\% mengatakan puas dan $4,7 \%$ tidak puas. pada dimensi daya tanggap $63,3 \%$ mengatakan puas dan 2,7\% tidak puas. Pada dimensi jaminan kesehatan $66,7 \%$ 
mengatakan puas dan $2,7 \%$ tidak puas. Pada dimensi empati $65,3 \%$ mengatakan puas dan $2 \%$ tidak puas, dan dari segi penampilan $70 \%$ mengatakan puas dan $2 \%$ tidak puas. Angka ini menunjukkan kualitas pelayanan $76,89 \%$ memuaskan .

Penelitian yang dilakukan di RSU daerah sekayu menunjukkan 65 orang ( $44,5 \%$ ) bahwa mutu kesehatan tidak baik dan 69 orang $(47,3 \%)$ menyatakan baik kepuasan pasien. Maka dapat disimpulkan bila pelayanan kesehatan tidak dilakukan dengan baik maka akan menimbulkan ketidakpuasan dari pasien sebagai pengguna jasa (Syahputra, 2015).

\section{METODE PENELITIAN}

Jenis penelitin ini bersifat survey analitik dengan menggunakan desain studi cross-sectional. Populasi penelitian yaitu pasien BPJS dengan jumlah kunjungan Bulan Desember Tahun 2017 sebanyak 592 pasien.

Diperoleh jumlah sampel dengan menggunakan rumus slovin (Sugiyono, 2017).

$$
\begin{gathered}
n=\frac{N}{1+\left(N \cdot e^{2}\right)} \\
n=\frac{592}{1+\left(592 \cdot 0,1^{2}\right)} \\
n=85
\end{gathered}
$$

\section{Berdasarkan}

survey pendahuluan yang didapatkan bahwa jumlah pasien 85 orang dengan karakteristik umur, pendidikan dan lama rawat inap yang berbeda-beda. Selanjutnya peneliti melakukan observasi melalui wawancara adanya keluhan dari pasien jadwal pelayanan rumah sakit kurang tepat seperti visit dokter dinas sehingga pasien menunggu lama, tenaga kesehatan ketika menjelaskan keluhan pasien kurang, lingkungan ruang rawat inap disamakan dengan jenis penyakit yang berbeda dan satu ruangan banyak, jaminan yang diberikan tenaga kesehatan kurang, dan perhatian kepada pasien masih kurang.

Keterangan :

$n=$ Jumlah sampel

$\mathrm{N}=$ Jumlah populasi

$\mathrm{e}=$ Sampling eror digunakan nilai $10 \%(0,1)$.

Teknik Pengambilan Sampel menggunakan simple random sampling dan ditentukan kriteria inklusi (notoatmodjo, 2012), yaitu Bersedia menjadi responden, Pasien dengan usia mulai 17 tahun, dan yang minimal tiga hari di ruang rawat inap. kriteria ekslusi yaitu yang tidak bersedia menjadi responden dan responden yang sedang merasa cemas dan gelisah.

\section{HASIL PENELITIAN}

Tabel 1

Distribusi Frekuensi Responden.

\begin{tabular}{ll|l|l}
\hline No & Karakteristik & Jumlah (n) & Persentase (\%) \\
\hline $\mathbf{1}$ & Jenis Kelamin & & \\
\cline { 2 - 4 } & Laki laki & 48 & 56,5 \\
& Perempuan & 37 & 43,5 \\
\cline { 2 - 4 } & Total & $\mathbf{8 5}$ & $\mathbf{1 0 0}$ \\
\hline $\mathbf{2}$ & Umur & & \\
\cline { 2 - 4 } & $17-30$ tahun & 18 & 21,2 \\
& $31-44$ tahun & 23 & 27,1 \\
& $45-58$ tahun & 22 & 25,9 \\
& $59-72$ tahun & 16 & 18,8 \\
& $73-86$ tahun & 6 & 7,1 \\
\hline & Total & $\mathbf{8 5}$ & $\mathbf{1 0 0}$ \\
\hline
\end{tabular}




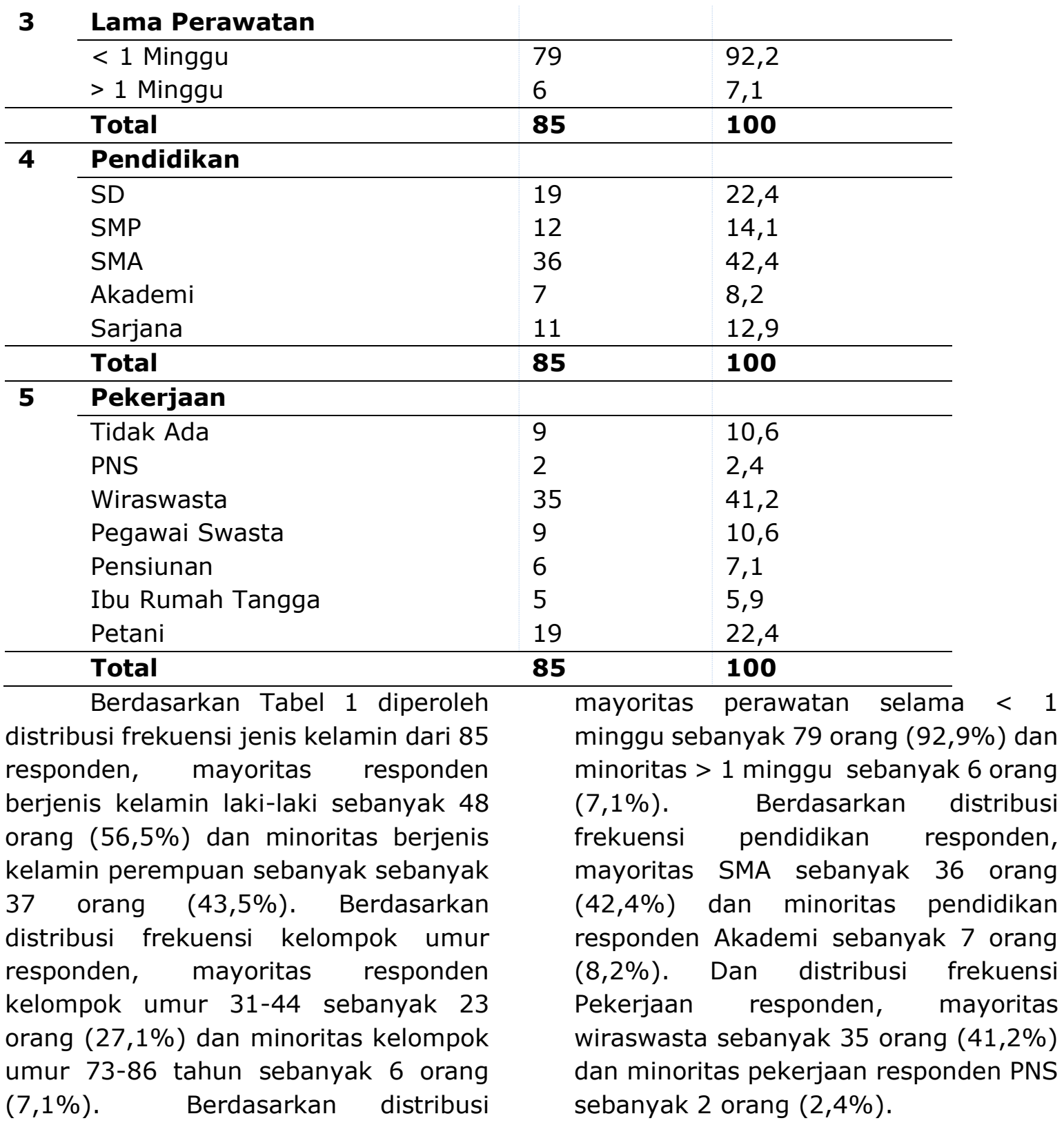

frekuensi lama perawatan responden,

Tabel 2

Distribusi Frekuensi Berdasarkan Variabel Bebas Penelitian

\begin{tabular}{lll}
\hline Variabel & Jumlah (n) & Persentase (\%) \\
\hline Bukti Fisik & & \\
Baik & 41 & 48,2 \\
Tidak Baik & 44 & 51,8 \\
\hline Kehandalan & & \\
Baik & 42 & 49,4 \\
Tidak Baik & 43 & 50,6 \\
\hline Daya Tanggap & & \\
Baik & 32 & 37,6 \\
Tidak Baik & 53 & 62,4 \\
\hline
\end{tabular}




\begin{tabular}{lll}
\hline Jaminan & 47 & 55,3 \\
Baik & 38 & 44,7 \\
Tidak Baik & 37 & 43,5 \\
\hline Perhatian & 48 & 56,5 \\
Baik & & \\
Tidak Baik & 41 & 48,2 \\
\hline Kepuasan Pasien & 44 & 51,8 \\
Puas & & \\
\hline
\end{tabular}

Berdasarkan Tabel 2 Diatas Dapat Dilihat Bahwa Pelayanan Bukti Fisik Dengan Mayoritas 44 Orang $(51,8 \%)$ Menyatakan Buktii Fisik Tidak Baik Dan Minoritas Sebanyak 41 Orang $(48,2 \%)$ Menyatakan Bukti Fisik Baik. Berdasarkan Analisis Kehandalan Mayoritas Sebanyak 43 Orang $(50,6 \%)$ Menyatakan Kehandalan Tidak Baik Dan Minoritas Sebanyak 42 Orang $(49,4 \%)$ Menyatakan Kehandalan Baik. Berdasarkan Analisis Daya Tanggap Mayoritas Sebanyak 53 Orang $(62,4 \%)$ Menyatakan Daya Tanggap Tidak Baik Dan Minoritas Sebanyak 32 Orang
(37,6\%) Menyatakan Ketanggapan Baik. Berdasarkan Analisis Jaminan Mayoritas Sebayak 47 Orang (55,3\%) Menyatakan Jaminan Baik Dan Minoritas Sebanyak 38 Orang (44,7\%) Menyatakan Jaminan Tidak Baik. Berdasarkan Analisis Perhatian Mayoritas Sebanyak 48 Orang (56,5\%) Menyatakan Perhatian Tidak Baik Dan Minoritas Sebanyak 37 Orang (43,5\%) Menyatakan Perhatian Baik. Ditinjau Dari Kepuasan Pasien Mayoritas Menyatakan Tidak Puas Sebanyak 44 Orang $(51,8 \%)$ Dan Minoritas Sebanyak 41 Orang $(48,2 \%)$ Menyatakan Puas.

Tabel 3

Hubungan bukti fisik dengan kepuasan pasien.

\begin{tabular}{lccccccc}
\hline \multirow{2}{*}{ Bukti Fisik } & \multicolumn{4}{c}{ Kepuasan Pasien } & & \multirow{2}{*}{ Total } & p value \\
\cline { 2 - 7 } & \multicolumn{4}{c}{ Puas } & \multicolumn{4}{c}{ Puas } & & & \\
\cline { 2 - 7 } & $\mathrm{n}$ & $\%$ & $\mathrm{n}$ & $\%$ & $\mathrm{n}$ & $\%$ & \\
\hline Baik & 26 & 63,4 & 15 & 36,6 & 41 & 100 & \\
\hline Tidak Baik & 15 & 34,1 & 29 & 65,9 & 44 & 100 & 0,013 \\
\hline
\end{tabular}

Hasil analisis bivariat di dapatkan $p$ value $=0,013$ ( $p$ value $<$ $0,05)$, maka Ho ditolak dan Ha diterima berarti ada hubungan pelayanan bukti fisik dengan Kepuasan Pasien

Tabel 4

Hubungan Kehandalan Dengan Kepuasan Pasien.

\begin{tabular}{|c|c|c|c|c|c|c|c|}
\hline \multirow{3}{*}{ Kehandalan } & \multicolumn{4}{|c|}{ Kepuasan Pasien } & \multirow{2}{*}{\multicolumn{2}{|c|}{ Total }} & \multirow[b]{2}{*}{ P Value } \\
\hline & \multicolumn{2}{|c|}{ Puas } & \multicolumn{2}{|c|}{$\begin{array}{l}\text { Tidak } \\
\text { Puas }\end{array}$} & & & \\
\hline & $\mathrm{N}$ & $\%$ & $\mathrm{~N}$ & $\%$ & $\mathrm{~N}$ & $\%$ & \\
\hline Baik & 28 & 66,7 & 14 & 33,3 & 42 & 100 & \\
\hline Tidak Baik & 13 & 30,2 & 30 & 69,8 & 43 & 100 & 0,002 \\
\hline
\end{tabular}


Hasil analisis bivariat di dapatkan $p$ value $=0,002$ ( $p$ value $<0,05)$, maka Ho ditolak dan Ha diterima berarti ada hubungan kehandalan dengan kepuasan pasien.

Tabel 5

Hubungan daya tanggap dengan kepuasan pasien.

\begin{tabular}{cccccccc}
\hline \multirow{2}{*}{$\begin{array}{c}\text { Daya } \\
\text { Tanggap }\end{array}$} & \multicolumn{4}{c}{ Puas } & \multicolumn{4}{c}{ Tidak Puas } & \multicolumn{1}{c}{ Total } & p value \\
\cline { 2 - 7 } & $\mathrm{n}$ & $\%$ & $\mathrm{n}$ & $\%$ & $\mathrm{n}$ & $\%$ & \\
\hline Baik & 21 & 65,6 & 11 & 34,4 & 32 & 100 & 0,023 \\
\hline Tidak Baik & 20 & 37,7 & 33 & 62,3 & 53 & 100 & \\
\hline
\end{tabular}

Hasil analisis bivariat di dapatkan $p$ value $=0,023$ ( $p$ value $<0,05)$, maka Ho ditolak dan Ha diterima berarti ada hubungan Daya Tanggap dengan dengan Kepuasan Pasien.

Tabel 6

Hubungan jaminan dengan kepuasan pasien.

\begin{tabular}{|c|c|c|c|c|c|c|c|}
\hline \multirow{3}{*}{ Jaminan } & \multicolumn{7}{|c|}{ Kepuasan Pasien } \\
\hline & \multicolumn{2}{|c|}{ Puas } & \multicolumn{2}{|c|}{ Tidak Puas } & \multicolumn{2}{|c|}{ Total } & \multirow[t]{2}{*}{ p value } \\
\hline & $n$ & $\%$ & $\mathrm{n}$ & $\%$ & $\mathrm{n}$ & $\%$ & \\
\hline Baik & 23 & 48,9 & 24 & 51,1 & 47 & 100 & 1,000 \\
\hline Tidak Baik & 18 & 47,4 & 20 & 52,6 & 38 & 100 & \\
\hline
\end{tabular}

Hasil analisis bivariat di dapatkan $p$ value $=1,000$ ( $p$ value $>0,05)$, artinya Ho diterima dan $\mathrm{Ha}$ ditolak

Tabel 7

Hubungan perhatian dengan kepuasan pasien.

\begin{tabular}{|c|c|c|c|c|c|c|c|}
\hline \multirow{3}{*}{ Empati } & \multicolumn{7}{|c|}{ Kepuasan Pasien } \\
\hline & \multicolumn{2}{|c|}{ Puas } & \multicolumn{2}{|c|}{ Tidak Puas } & \multicolumn{2}{|c|}{ Total } & \multirow{2}{*}{ p value } \\
\hline & $\mathrm{n}$ & $\%$ & $\mathrm{n}$ & $\%$ & $\mathrm{n}$ & $\%$ & \\
\hline Baik & 22 & 59,5 & 15 & 40,5 & 37 & 100 & 0,110 \\
\hline Tidak Baik & 19 & 39,6 & 29 & 60,4 & 48 & 100 & \\
\hline
\end{tabular}

Hasil analisis bivariat di dapatkan $p$ value $=0,110$ ( $p$ value $>0,05)$, maka Ho diterima dan Ha ditolak berarti tidak

\section{PEMBAHASAN}

Hubungan bukti fisik dengan kepuasan pasien.

Hasil pengisian kuesioner dari 44 responden yang menilai tidak baik pelayanan bukti fisik mayoritas responden menyatakan tidak puas sebanyak 29 orang $(65,9 \%)$ dan berarti tidak ada hubungan jaminan dengan Kepuasan Pasien. 
minoritas tidak puas sebanyak 15 orang $(36,6 \%)$.

Hal ini menguatkan teori parasuraman zeithml (1998), wujud

\section{Hubungan Kehandalan dengan kepuasan pasien.}

Dari 43 responden yang menilai tidak baik tentang pelayanan kehandalan mayoritas responden menyatakan tidak puas sebanyak 30 orang $(69,8 \%)$ dan minoritas puas sebanyak 13 orang $(30,2 \%)$.

Dari 42 responden yang menilai baik tentang pelayanan kehandalan mayoritas responden menyatakan puas

Hubungan daya tanggap dengan kepuasan pasien.

Dari 53 responden yang menilai tidak baik tentang pelayanan Daya Tanggap mayoriras responden menyatakan tidak puas sebanyak 33 orang $(62,3 \%)$ dan minoritas puas sebanyak 20 orang $(37,3$

Dari 32 responden yang menilai baik tentang pelayanan Daya Tanggap mayoritas responden menyatakan puas

\section{Hubungan jaminan dengan kepuasan pasien.}

Dari 47 responden yang menilai baik tentang pelayanan jaminan mayoritas responden menyatakan tidak puas sebanyak 24 orang $(51,1 \%)$ dan minoritas puas 23 orang (48,9\%).

Dari 38 responden yang menilai tidak baik tentang pelayanan jaminan mayoritas responden menyatakan tidak puas sebanyak 20 orang $(52,6 \%)$ dan

\section{Hubungan perhatian dengan kepuasan pasien.}

Dari 48 responden yang menilai tidak baik tentang pelayanan perhatian mayoritas responden menyatakan tidak puas sebanyak 29 orang $(60,4 \%)$ dan minoritas puas sebanyak 19 orang $(39,6 \%)$.

Dari 37 responden yang menilai baik tentang pelayanan empati mayoritas responden menyatakan puas kenyataan secara fisik yang meliputi penampilan dan kelengkapan fasilitas fisik seperti ruang perawatan dan rawat inap.

sebanyak 28 orang $(66,7 \%)$ dan minoritas tidak puas sebanyak 14 orang $(33,3 \%)$.

Hal in menguatkan teori parasuraman zeithml (1998). Penilaian kualitas pelayanan dilihat dari kemampuan institusi berkaitan dengan ketetapan waktu pelayanan.

sebanyak 21 orang $(65,6 \%$ dan minoritas tidak puas sebanyak 11 orang (34,4\%).

Hal ini menguatkan teori parasuraman zeithml (1998), respon atau kesiapan karyawan dalam membantu pelanggan dan cepat merespon.

minoritas puas sebanyak 18 orang $(47,4 \%)$.

Hal ini menguatkan teori parasuraman zeithhml (1998), kemampuan tenaga kesehatan atas pengetahuan terhadap memberikan bantuan secara tepat, jaminan keselamatan dan memberikan keamanan.

sebanyak 22 orang $(59,5 \%)$ dan minoritas tidak puas sebanyak 15 orang $(40,5 \%)$.

Hal ini menguatkan teori parasuraman zeithml (1998), perhatian secara individual yang diberikan rumah sakit terhadap pasien dan keluarganya seperti memberikan semangat supaya cepat sehat. 


\section{KESIMPULAN}

Hasil penelitian ini menyimpulkan bahwa ada hubungan anatara bukti fisik $(0,013)$, kehandalan $(0,002)$ dan daya tanggap $(0,023)$. Dan

\section{SARAN}

1. Bagi Instansi Rumah Sakit agar meningkatkan mutu pelayanan terutama pelayanan BPJS.

2. Kepada peneliti selanjutnya untuk melakukan penelitian yang berhubungan dengan mutu dan kepuasan pasien.

tidak ada hubungan jaminan $(1,000)$ dan perhatian $(0,110)$ dengan kepuasan pasien BPJS rawat inap di RS santa Elisabeth medan. 


\section{DAFTAR PUSTAKA}

Balitbang Kota Medan. Identifikasi Tingkat Kepuasan Masyarakat Terhadap Jamkesmas. 2013.

Kemenkes R I. Laporan Akuntabilitas Kinerja Kementerian Kesehatan Tahun 2014.

Notoatmodjo S. Metodologi Penelitian Kesehatan. Jakarta: Rineka Cipta; 2012.

Parasuraman, Zeithaml VA, Berry LL. SERVQUAL: A Multiple- item scale for Measuring Consumer Perceptions of Service Quality. 1998.
Perpes No. 1 tahun 2014. Penyelenggaraan Jaminan Kesehatan.

Rumah Sakit Santa Elisabeth. Laporan Tahunan . Medan: 2017.

Sugiyono. Metode Penelitian Kuantitatif, Kualitatif dan R\&D. Jakarta: Penerbit Alfabeta; 2017.

Syahputra, Diman, Agus. 2015. Hubungan mutu pelayanan BPJS Kesehatan dengan kepuasan pasien di instalasi rawat jalan kelas II rumah sakit umum daerah sekayu. 